\title{
ASSESSMENT OF BOTTOM-OF-ATMOSPHERE REFLECTANCE IN LIDAR DATA AS REFERENCE FOR HYPERSPECTRAL IMAGERY
}

\author{
A. Roncat ${ }^{\mathrm{a}, *}$, N. Pfeifer ${ }^{\mathrm{a}}$, and C. Briese ${ }^{\mathrm{b}}$ \\ ${ }^{\text {a }}$ Research Groups Photogrammetry and Remote Sensing, Department of Geodesy and Geoinformation, TU Wien, Vienna, Austria \\ (andreas.roncat, norbert.pfeifer) @geo.tuwien.ac.at ww .geo.tuwien.ac.at \\ ${ }^{\mathrm{b}}$ EODC Earth Observation Data Centre for Water Resources Monitoring GmbH, Vienna, Austria \\ christian.briese@eodc.eu. Ww. eodc.eu
}

Commission VII, WG VII/6

KEY WORDS: Laser Scanning/lidar, Hyperspectral, Bottom-of-Atmosphere Reflectance, Radiometric Calibration

\begin{abstract}
:
While airborne lidar has confirmed its leading role in delivering high-resolution 3D topographic information during the last decade, its radiometric potential has not yet been fully exploited. However, with the increasing availability of commercial lidar systems which (a) make use of full-waveform information and (b) operate at several wavelengths simultaneously, this potential is increasing as well. Radiometric calibration of the full-waveform information mentioned before allows for the derivation of physical target surface parameters such as the backscatter coefficient and a diffuse reflectance value at bottom of atmosphere (BOA), i.e. the target surface.

With lidar being an active remote sensing technique, these parameters can be derived from lidar data itself, accompanied by the measurement or estimation of reference data for diffuse reflectance. In contrast to this, such a radiometric calibration for passive hyperspectral imagery (HSI) requires the knowledge and/or estimation of much more unknowns. However, in case of corresponding wavelength(s) radiometrically calibrated lidar datasets can deliver an areawide reference for BOA reflectance.

This paper presents criteria to check where the assumption of diffuse BOA reflectance behaviour is fulfilled and how these criteria are assessed in lidar data; the assessment is illustrated by an extended lidar dataset. Moreover, for this lidar dataset and an HSI dataset recorded over the same area, the corresponding reflectance values are compared for different surface types.
\end{abstract}

\section{INTRODUCTION}

Airborne hyperspectral imagery (HSI) data contains highly rich spectral information with ground-sampling distances typically in the range of $0.5-5 \mathrm{~m}$. HSI systems cover a spectral range from visible to infra-red in up to hundreds of spectral bands. HSI data allows for precise mapping and classification of surfaces, e.g. for the estimation of biochemical parameters (Reusen et al., 2017).

However, HSI signals are influenced by several geometric and physical parameters; decomposing the single contributions in the sense of radiometric calibration is a difficult task. Airborne lidar, also referred to airborne laser scanning (ALS) delivers areawide $3 \mathrm{D}$ topographic information in high precision and in up to decimetre resolution. Therefore, it has already proven to be valuable in a geometric sense for facilitating radiometric calibration of HSI data (Schneider et al., 2014).

ALS systems store radiometric information, commonly referred to as intensity, additionally to the $3 \mathrm{D}$ information they deliver. Especially full-waveform systems such as the RIEGL LMS-Q series (Riegl LMS, 2016) and multi-spectral systems such as TeledyneOptech's Titan (Teledyne Optech Inc., 2017) exhibit a huge potential in a radiometric sense. While studies of ALS/HSI data fusion have already been performed, e.g. based on raw ALS amplitude data (Buddenbaum et al., 2013), the full radiometric information delivered by ALS sensors is not yet fully exploited in the context of fusing full-waveform ALS data and HSI data. Thorough radiometric calibration of full-waveform ALS data allows for the derivation of a surface or bottom-of-atmosphere (BOA) reflectance value. In order to fuse HSI and ALS intensity and to perform cross-calibration, such surfaces are required to act as homogeneous targets and Lambertian (=diffuse) reflectors (Brell et al., 2017).
In this study, we evaluate where reference BOA reflectance can be reliably derived from both ALS point clouds and radiometric information and how the criteria for their validity can be assessed in such ALS datasets. The proposed workflow is illustrated by means of an extended full-waveform lidar campaign and an HSI campaign, both recorded over the town of Zermatt, located in the canton of Valais, Switzerland.

The paper is organized as follows: Radiometric calibration of both ALS and passively sensed HSI data are presented in Section 2 followed by the method for assessing reference areas and values for diffuse reflectance in Section 3 . The method is illustrated by the aforementioned ALS dataset. Additionally, ALSand HSI-derived reflectance values are compared for selected areas of four different surface types. The results of this comparison are given in Section 4, conclusions are drawn in the last section.

\section{THEORY}

In this section, we will present the physical-mathematical framework for radiometric calibration of both lidar and passively sensed optical data.

The basic relation of the transmitted power of a laser pulse $P_{t}$ and the recorded echo power $P_{e}$ is given by the radar equation (Jelalian, 1992 Wagner, 2010):

$$
P_{e}=\frac{D_{r}^{2}}{4 \pi R^{4} \beta_{t}^{2}} P_{t} \sigma \eta_{\mathrm{SYS}} \eta_{\mathrm{ATM}},
$$

with $\beta_{t}$ being the beamwidth of the transmitted signal, $R$ denoting the distance from the sensor to the target, $D_{r}$ the receiving aperture diameter, $\eta_{\mathrm{SYS}}$ the system transmission factor and $\eta_{\mathrm{ATM}}$ the atmospheric transmission factor. The scattering cross-section 
$\sigma\left(\right.$ in $\left.\mathrm{m}^{2}\right)$ is of special interest for the comparison with HSI data as it summarizes target characteristics:

$$
\sigma:=\frac{4 \pi}{\Omega_{S}} \rho A_{L} \cos \vartheta
$$

The unitless quantity $\rho$ is the reflectance of the target surface in scattering direction, also referred to as bottom-of-atmosphere reflectance. The term $A_{L}\left[\mathrm{~m}^{2}\right]$ is the area of the laser footprint, i.e. the area formed by the intersection of the cone and a sphere with centre at the laser's position and radius $R$ corresponding to the distance from the laser to the target, while $\Omega_{S}[\mathrm{sr}]$ is the solid angle of the scattering cone. The angle $\vartheta$ is the incidence angle, i.e. the angle formed by the direction of the laser beam and the local surface normal of the target surface; see Figure 1.

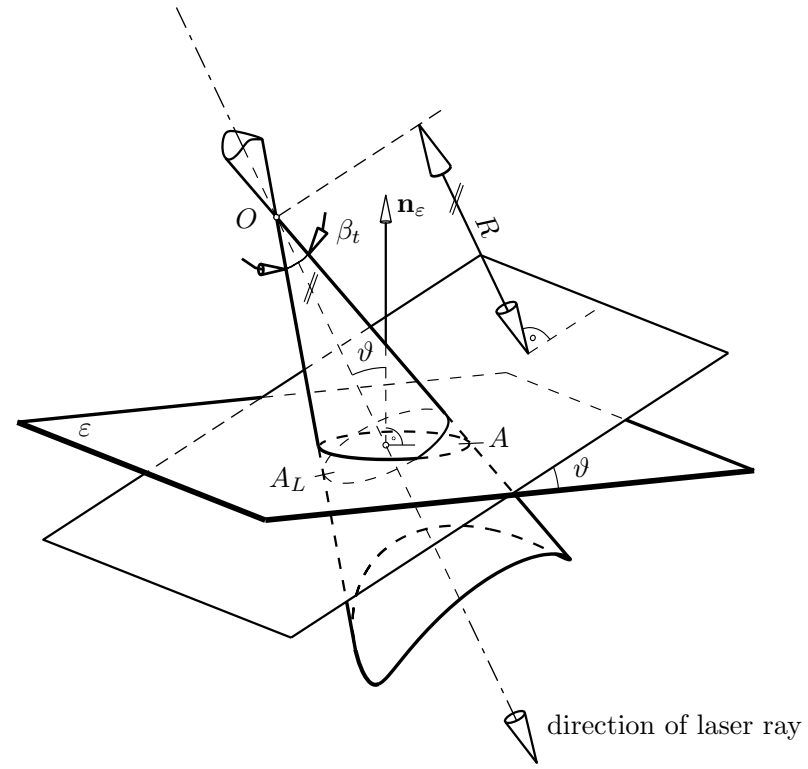

Figure 1: Geometric parameters of the radar equation. The angle $\vartheta$ formed by the laser ray and the normal of of the target plane $\varepsilon$ is called incidence angle (Roncat et al., 2012). Its precise determination is essential for calculating the diffuse BOA reflectance $\rho_{d}$.

In a monostatic configuration, i.e. the transmitter and receiver being close together, $\sigma$ is to be considered as backscatter crosssection. This is the case for practically all airborne lidar systems. Only in the case of diffuse reflectance behaviour (Lambertian reflectance), the reflectance value can be regarded as a reference for HSI data. In this case, the scattering solid angle $\Omega_{S}=\pi$ and the diffuse BOA reflectance $\rho_{d}$ is derived as

$$
\rho_{d}=\frac{\sigma}{4 A_{L} \cos \vartheta} .
$$

The retrieval of $\sigma$ and/or $\rho_{d}$ is known as radiometric calibration. For this purpose, unknown but constant quantities are summarized as calibration constant, determined by means of reference targets which might be surfaces of (assumed) known and constant reflectance (Wagner et al., 2006), natural or artificial surfaces with calibrated reflectance behaviour (Lehner and Briese, 2010, Kaasalainen et al., 2009).

The actual formulation of the calibration constant and sequence of calibration steps may vary. For further details concerning radiometric calibration see (Wagner, 2010 Briese et al., 2012, Roncat, 2014), among others.

The calculation of the diffuse reflectance requires knowledge of the spatial neighbourhood of this point, expressed e.g. by the lo- cal surface-normal vector, commonly derived using the 3D point cloud of the same lidar campaign.

In addition to the aforementioned factors to be considered in radiometric calibration, passively sensed data are also dependent on various other quantities. In a first step, a gain factor and an offset have to be applied, transferring the digitized pixel values to at-sensor radiances $L_{\lambda}$, given in $W /\left(\mathrm{m}^{2} \mathrm{sr} \mu \mathrm{m}\right)$ or equivalent. To derive further the surface reflectance $\rho$, the following parameters are to be considered (Moran et al., 1992, Chander et al., 2009):

- the mean solar exo-atmospheric irradiance,

- the solar zenith angle,

- the Earth-Sun distance,

- the path radiance,

- the atmospheric transmittance in viewing and illumination direction, resp., and

- the downwelling diffuse irradiance.

Their values are commonly given in models of coarser resolution than the one of imagery data. In analogy to ALS, they may be partly summarized in another, HSI-specific, calibration constant (Brell et al., 2017).

\section{METHOD}

The ALS dataset investigated in this study was acquired on October 14, 2010 over the town of Zermatt (Canton of Valais, Switzerland). The data were recorded in the shortwave infra-red domain (wavelength $1550 \mathrm{~nm}$ ) by a RIEGL LMS-Q680i full-waveform instrument (Riegl LMS, 2016) at a pulse repetition rate of $150 \mathrm{kHz}$ in a spatial sampling of approximately $5 \mathrm{pts} / \mathrm{m}^{2}$ at ground (Nussberger, 2012). The area is shown in Figure 2

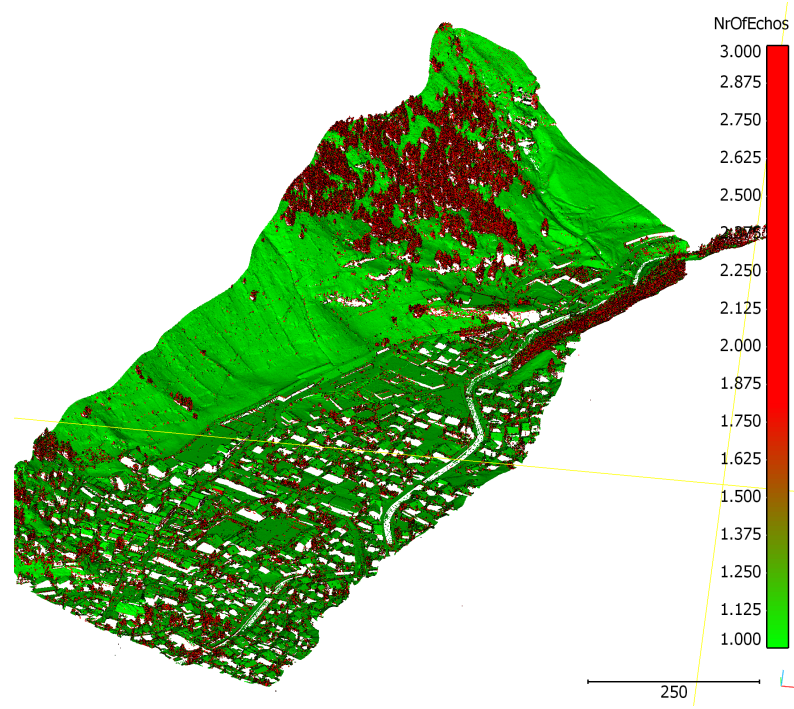

Figure 2: ALS point cloud of the town of Zermatt (canton of Valais, Switzerland), view towards North-West; green: single echoes, red: two or more echoes per shot.

The aerial HSI data were acquired over the same area on July 1, 2010, using the APEX instrument (Hueni et al., 2009). This instrument covers a spectral range from $380-2500 \mathrm{~nm}$ in 284 
spectral bands. For comparison with the ALS data, a BOA reflectance grid was calculated for band 168 (wavelength $1549 \mathrm{~nm}$, FWHM $11.9 \mathrm{~nm}$ ) in the spatial resolution of $2 \mathrm{~m}$ grid size (Nussberger, 2012).

By means of the ALS dataset described above, we present a method how to detect suitable areas as reference areas for diffuse BOA reflectance. Each criterion is illustrated by a colour-coded version of the same point cloud. The points where the criterion is fulfilled are shown in blue and green whereas the points where the criterion is only partly or not fulfilled are shown in yellow and red, respectively.

\section{Criterion 1: Opaque and extended targets}

The first criterion is the presence of opaque and extended targets, i.e. the target surface covers the full laser beam. This criterion can be evaluated in two ways: (a) by the number of echoes per shot (see Figure 2) - only single echoes may represent extended targets, and (b) by the echo ratio. The latter is a unitless quantity comparing the the number of points in the $3 \mathrm{D}$ and the $2 \mathrm{D}$ neighbourhood of a point, respectively; it ranges from 0 to 100 percent (Höfle et al., 2009). The higher the echo ratio, the higher the probability of opaque targets. The echo ratio of the Zermatt ALS dataset is shown in Figures 3 (overview) and 7/(detailed map view of a sub-set of the ALS data, located in the town centre of Zermatt). While the single-echo criterion and the echo-ratio criterion agree in most cases, they complement each other as they follow different geometries: the single-echo criterion is oriented along the (slanted) laser ray whereas the echo ratio is oriented along the vertical axis of the coordinate system of the used map projection. Therefore, the echo-ratio criterion is preferable for handling vertical structures in ALS data.

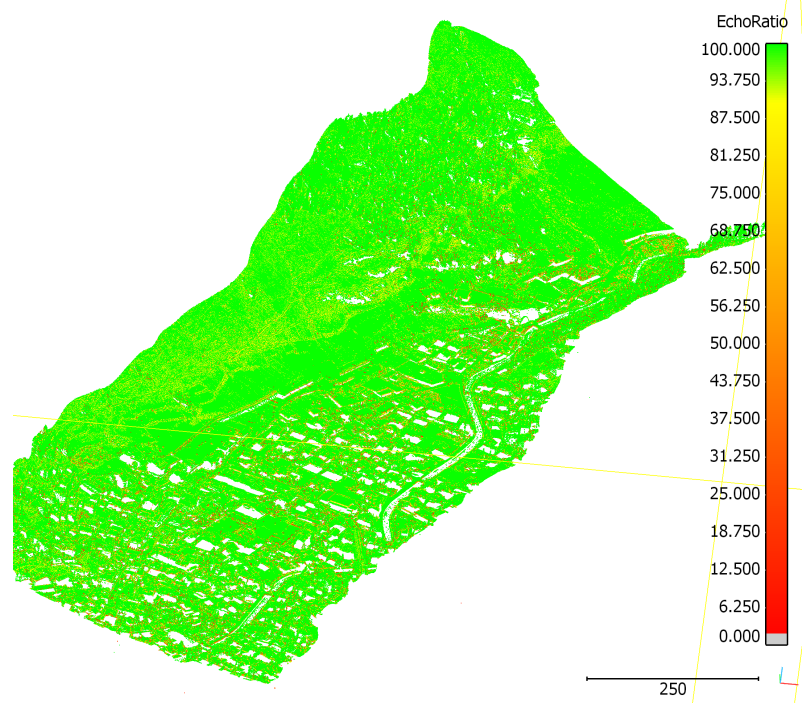

Figure 3: ALS point cloud of Figure 2 colour-coded by the echo ratio.

\section{Criterion 2: Diffuse reflectance behaviour}

This criterion is essential, as ALS and HSI data are in general captured from different positions. Therefore, only surfaces with diffuse, i.e. isotropic scattering behaviour may be taken into account. For assessing this criterion in an ALS dataset, we (a) exclude areas where the calculated reflectance value is outside the interval $[0,1]=[0 \%, 100 \%]$ (see Figure 4 ), as only positive reflectance values are meaningful and not more than the full amount of incident energy can reflected, respectively. Furthermore, (b) areas were exluded where significant differences in reflectance in overlapping areas of neighbouring flight strips appeared ((Lehner and Briese, 2010, Roncat et al., 2014); see Figures 5) and 7).

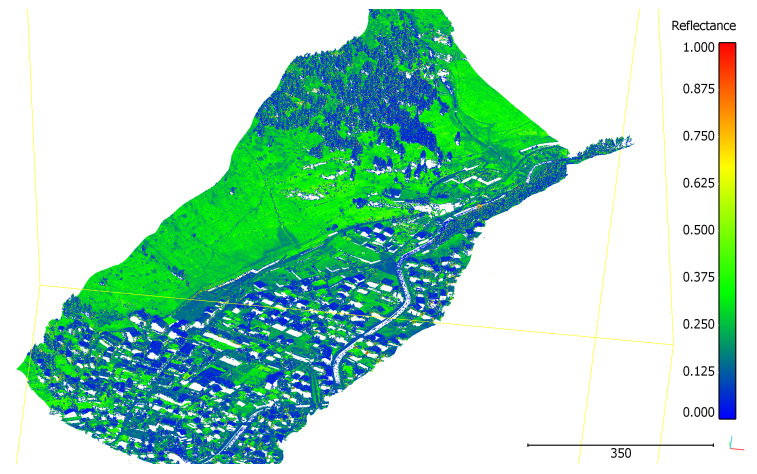

Figure 4: ALS point cloud of Figure 2 colour-coded by the calculated diffuse reflectance value.

While the first assessment can be performed in a single ALS flight strip, the latter needs the calculation of reflectance values for at least two flight strips and an intermediate gridding step.

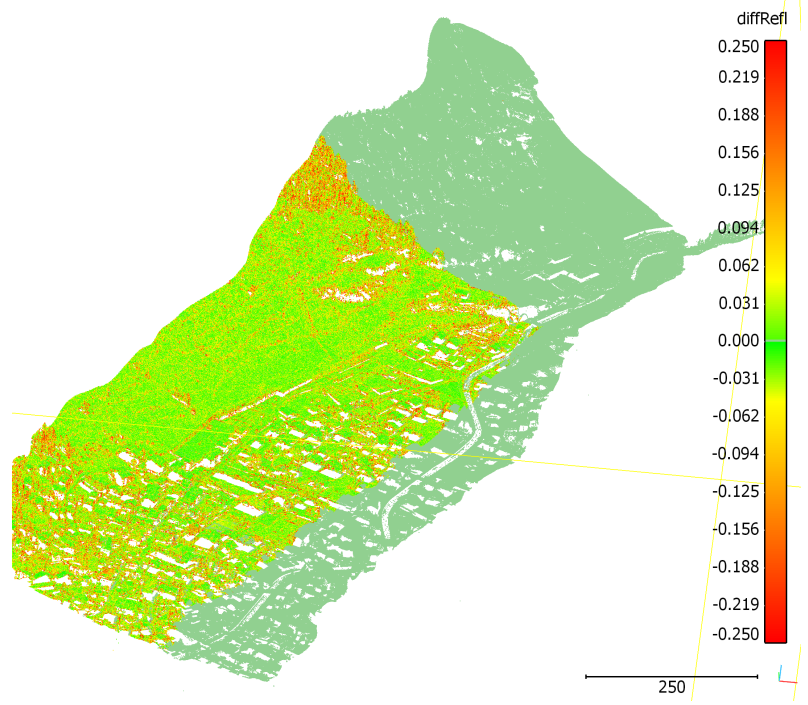

Figure 5: ALS point cloud of Figure 2 colour-coded by the absolute difference in diffuse reflectance value for overlapping flight strips.

\section{Criterion 3: Reliable estimation of the incidence angle $\vartheta$}

In case of diffuse surface reflectance, the signal strength of the scattered signal is only dependent on the illumination direction, given by $\vartheta$ and scaled by $\cos \vartheta$, but not dependent on the viewing direction. This criterion corresponds to the estimation of the local surface normal vector, commonly derived from the local neighbourhood of a 3D point in a robust least-squares adjustment. The $\sigma_{0}$ value a posteriori of this adjustment is an indicator for the accuracy of the adjustment results and therefore for the estimation of the incidence angle. Especially areas with high terrain roughness exhibit high $\sigma_{0}$ values and therefore less suited as reference areas than smooth areas, see Figures 6 and 7

Additionally, the ALS-derived and HSI-derived reflectance values were compared for four different surface types:

- rooftops

- meadows 


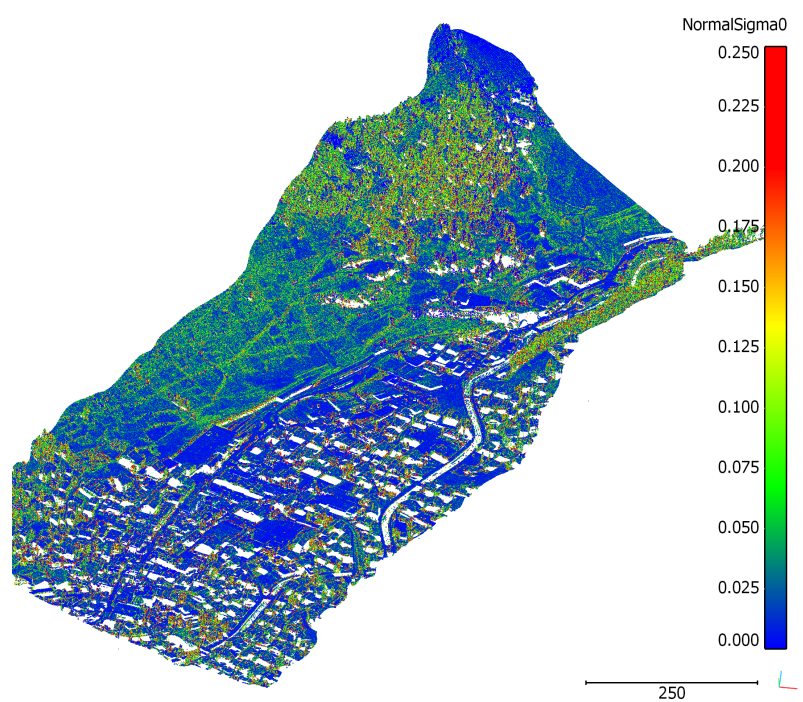

Figure 6: ALS point cloud of Figure 2 colour-coded by the $\sigma_{0}$ value a posteriori of normal vector estimation.
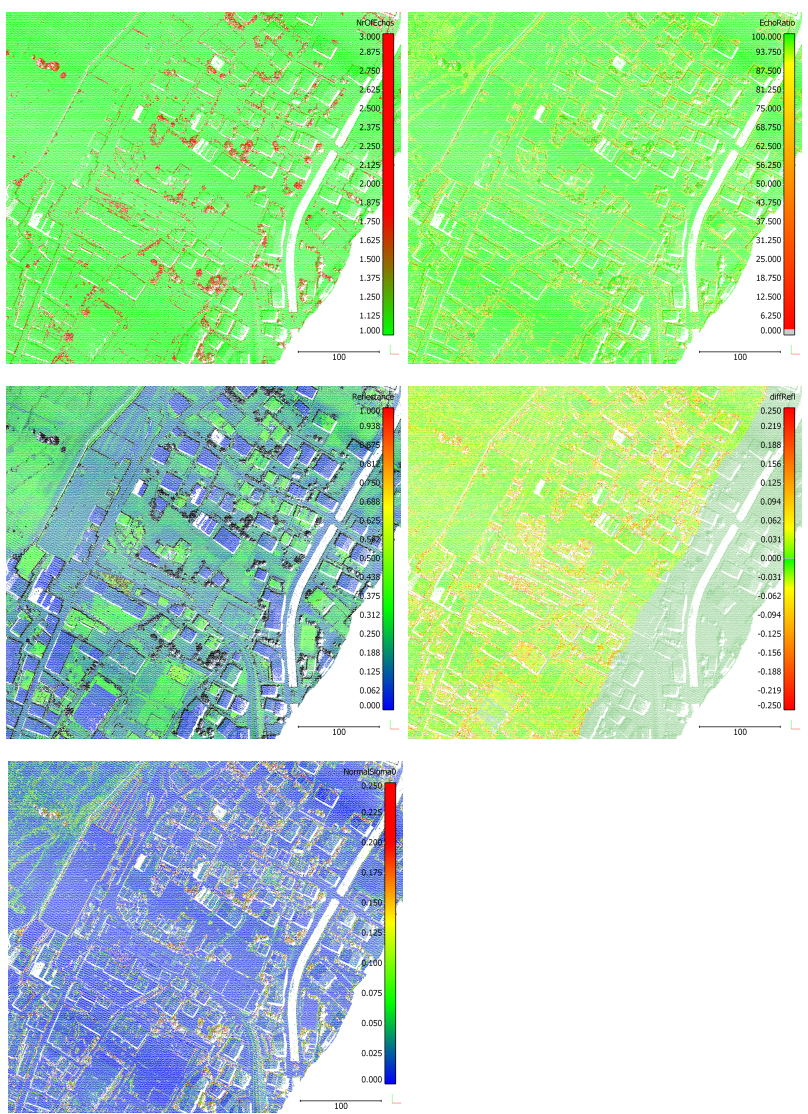

Figure 7: Criteria parameters in the town center of Zermatt (map view): Number of echoes (top left), Echo Ratio (top right), Reflectance value (center left), absolute difference of reflectance values (center right), $\sigma_{0}$ of normal vector estimation (bottom).

$$
\begin{aligned}
& \text { - forested vegetation } \\
& \text { - } \operatorname{river} \text { (Matter Vispa) }
\end{aligned}
$$

An overview of the selected areas is shown in Figure 8

\section{RESULTS}

The comparison of ALS- and HSI-dervied reflectances for the four selected surface types showed quite differing results. The correspondence for roof tops of buildings and meadows is by far better than for the other two surface types. This can be explained by the criteria given in the previous section: While roof tops as man-made structures mostly have a planar structure and are covered with opaque and non-specular materials, the reflectance behaviour can be considered as diffuse, allowing for a direct comparison of the two calculations of reflectance, as Figure 9 suggests.

Also meadows are mostly found on smooth terrain and show a diffuse reflectance behaviour, therefore allowing for a good coincidence of ALS- and HSI-derived reflectance; see Figure 10

In the case of rivers or water bodies in general, the situation is a bit more complicated: In the short-wave infra-red domain as used e.g. by the RIEGL LMS-Q680i ALS system, there is practically no diffuse reflectance at the water surface but specular reflectance and absorption as well as absorption by the water body. Therefore, only high reflectance values are found where the water surface is nearly perpendicular to the direction of the laser ray. Outside of these areas, the return signal strength reduces rapidly and therefore, only few echoes are found; see Figures 4 and 8 (bottom). This explains the over-estimation of reflectance in the ALS case in Figure 11

In high vegetation, multiple scattering appears between the vegetation layers, thus complicating the comparison of reflectance. Multiple scattering may appear which can be modeled by e.g. radiative transfer models using fractal tree models. The ALS return signal strength is, among other factors, mainly influenced by the canopy reflectance at the laser wavelength (Morsdorf et al., 2007. Morsdorf et al., 2009). However, the reflectance may change with the stage of the vegetation. As a result, ALS and HSI may not capture the "'same"' surface in case of differing acquisition dates of the respective data set. Furthermore, the criterion of extended targets is only fulfilled in few cases; see Figures 2 and 3 Also here, some areas show an overestimation of ALS-derived reflectance in comparison to the HSI-derived reflectance; see Figure 12

\section{DISCUSSION AND OUTLOOK}

This study dealt with the comparison of reflectance of (full-waveform) lidar and passively sensed hyperspectral imagery data. Lidar, as an active remote sensing technique, needs by far less assumptions for performing radiometric calibration. This has led to the motivation for testing lidar as a reference for diffuse reflectance in an area-wide sense in order to support radiometric calibration of hyperspectral imagery in according wavelength(s).

Criteria for the validity of the diffuse surface reflectance, assessable in an advanced lidar-data processing, were developed and presented by means of an extended airborne lidar campaign. A comparison of reflectance data was performed for four surface types (roof tops of buildings, meadows, river and high forested vegetation) within the aforementioned lidar and an HSI campaign performed over the same area. 


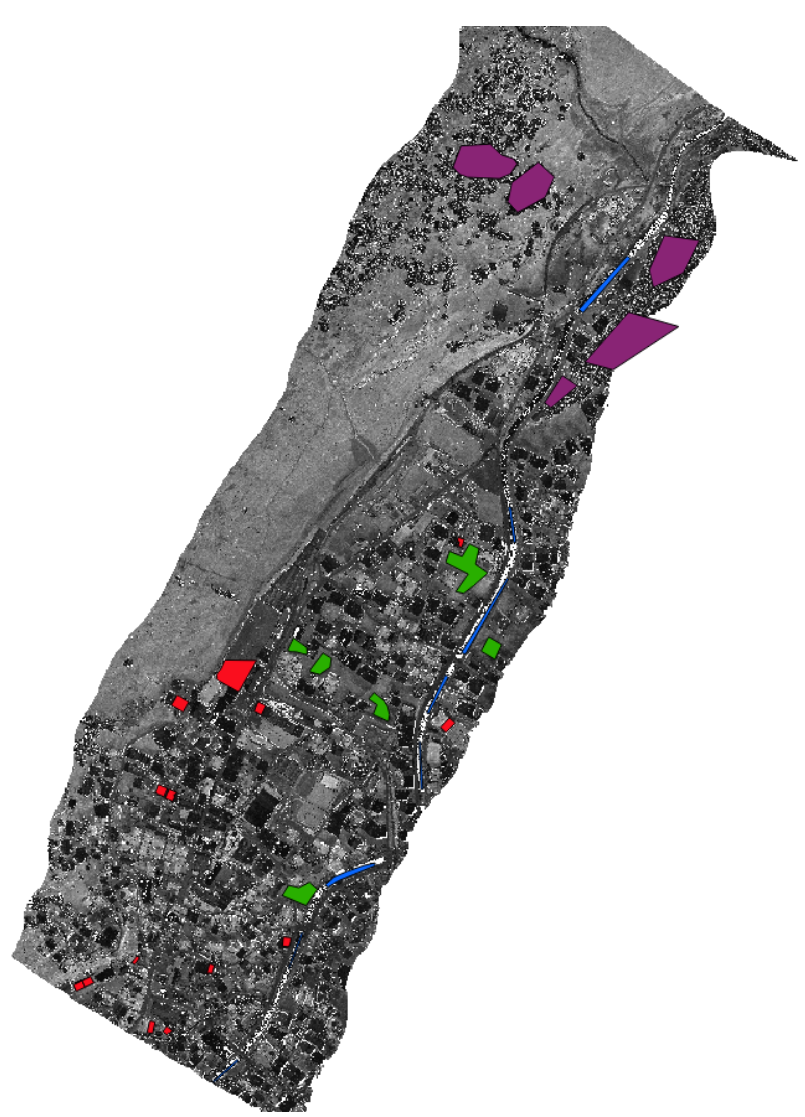

Figure 8: Overview of the areas of interest in the comparison of lidar and HSI datasets recorded over the town of Zermatt. The ALS-derived diffuse reflectance in the wavelength of $1550 \mathrm{~nm}$ is shown in the background. The test areas are shown as red (roof tops), blue (rivers), green (meadows) and purple polygons (high vegetationin forests)

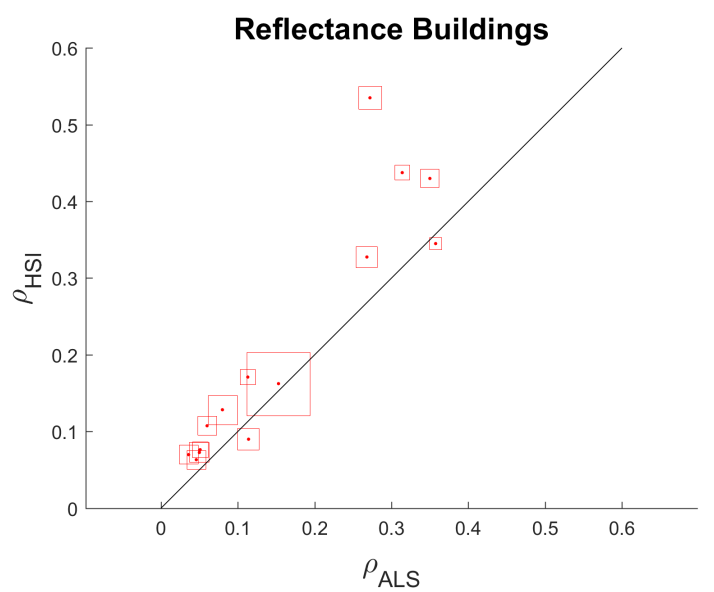

Figure 9: Reflectance comparison of ALS and HSI data for roof tops. The size of the red squares corresponds to the area of the respective roof top.

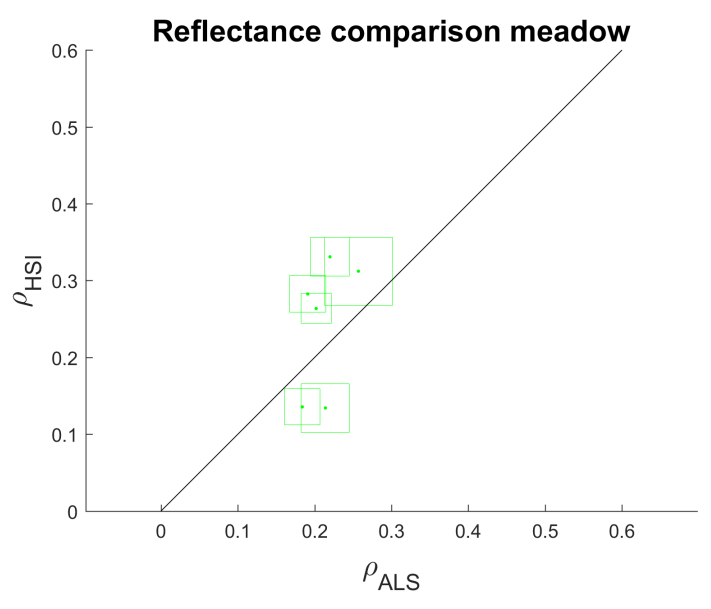

Figure 10: Reflectance comparison for meadows. The size of the green squares corresponds to the area covered by the single meadows.

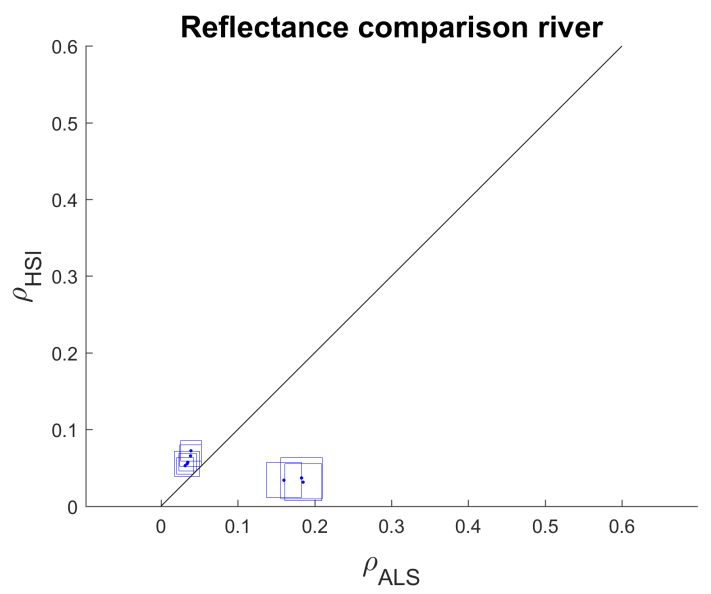

Figure 11: Reflectance comparison for river (Matter Vispa). The size of the blue squares corresponds to the area covered by the single polygons.

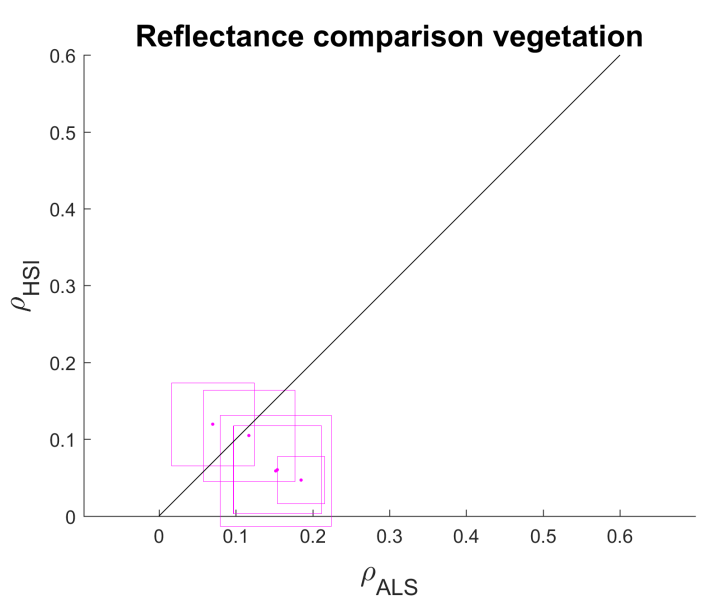

Figure 12: Reflectance comparison for high vegetation. The size of the purple squares corresponds to the area covered by the single vegetated areas. 
The reflectances were found comparable in case of the first two surface types where all three criteria were fulfilled, but less comparable in the case of the latter two surface types in which at least one criterion could in general not be assumed. This indicates the validity of our assumption. While this study concentrated on a single wavelength in the short-wave infra-red domain, current developments of multi-spectral and hyperspectral lidar systems give the motivation for further research in this field; see, among others, (Briese et al., 2012, Hakala et al., 2012, Wallace et al., 2014).

\section{ACKNOWLEDGEMENTS}

The research leading to these results has received funding from the European Union's 7th Framework Programme (FP7/2014 2018) under EUFAR2 contract no. 312609.

The Zermatt ALS dataset was provided by RSL (UZH) and processed using the ALS software suite Opals (OPALS, 2016).

The Zermatt APEX imaging reflectometer dataset has been acquired within the Swiss Earth Observatory Network (SEON) project and was processed using the APEX Processing and Archiving Facility (Hueni et al., 2009).

\section{REFERENCES}

Brell, M., Segl, K., Guanter, L. and Bookhagen, B., 2017. Hyperspectral and lidar intensity data fusion: A framework for the rigorous correction of illumination, anisotropic effects, and cross calibration. IEEE Transactions on Geoscience and Remote Sensing 55(5), pp. 2799-2810.

Briese, C., Pfennigbauer, M., Lehner, H., Ullrich, A., Wagner, W. and Pfeifer, N., 2012. Radiometric calibration of multiwavelength airborne laser scanning data. In: ISPRS Annals of the Photogrammetry, Remote Sensing and Spatial Information Sciences 1 (Part 7), Melbourne, Australia, pp. 335-340. ISSN: 1682-1750.

Buddenbaum, H., Seeling, S. and Hill, J., 2013. Fusion of fullwaveform lidar and imaging spectroscopy remote sensing data for the characterization of forest stands. International Journal of Remote Sensing 34(13), pp. 4511-4524.

Chander, G., Markham, B. L. and Helder, D. L., 2009. Summary of current radiometric calibration coefficients for landsat MSS, TM, ETM+, and EO-1 ALI sensors. Remote Sensing of Environment 113(5), pp. 893-903.

Hakala, T., Suomalainen, J., Kaasalainen, S. and Chen, Y., 2012. Full waveform hyperspectral lidar for terrestrial laser scanning. Optics Express 20(7), pp. 7119-7127.

Höfle, B., Mücke, W., Dutter, M., Rutzinger, M. and Dorninger, P., 2009. Detection of building regions using airborne LiDAR A new combination of raster and point cloud based GIS methods. In: Proceedings of the Geoinformatics Forum Salzburg, Salzburg, Austria, pp. 66-75.

Hueni, A., Biesemans, J., Meuleman, K., Dell'Endice, F., Schläpfer, D., Adriaensen, S., Kempenaers, S., Odermatt, D., Kneubuehler, M., Nieke, J. and Itten, K., 2009. Structure, components and interfaces of the airborne prism experiment (APEX) processing and archiving facility. IEEE Transactions in Geosciences and Remote Sensing 47(1), pp. 29-43.

Jelalian, A. V., 1992. Laser Radar Systems. Artech House, Boston.
Kaasalainen, S., Hyyppä, H., Kukko, A., Litkey, P., Ahokas, E., Hyyppä, J., Lehner, H., Jaakkola, A., Suomalainen, J., Akujarvi, A., Kaasalainen, M. and Pyysalo, U., 2009. Radiometric calibration of lidar intensity with commercially available reference targets. IEEE Transactions on Geoscience and Remote Sensing 47(2), pp. 588-598.

Lehner, H. and Briese, C., 2010. Radiometric calibration of full-waveform airborne laser scanning data based on natural surfaces. In: ISPRS Technical Commission VII Symposium 2010: 100 Years ISPRS - Advancing Remote Sensing Science. International Archives of the Photogrammetry, Remote Sensing and Spatial Information Sciences 38 (Part 7B), Vienna, Austria, pp. 360365 .

Moran, M. S., Jackson, R. D., Slater, P. N. and Teillet, P. M., 1992. Evaluation of simplified procedures for retrieval of land surface reflectance factors from satellite sensor output. Remote Sensing of Environment 41(2), pp. 169-184.

Morsdorf, F., Frey, O., Koetz, B. and Meier, E., 2007. Ray tracing for modeling of small footprint airborne laser scanning returns. In: ISPRS Workshop "Laser Scanning 2007 and SilviLaser 2007". International Archives of the Photogrammetry, Remote Sensing and Spatial Information Sciences 36 (Part 3/W52), pp. 294-299.

Morsdorf, F., Nichol, C., Malthus, T. and Woodhouse, I. H., 2009. Assessing forest structural and physiological information content of multi-spectral LiDAR waveforms by radiative transfer modelling. Remote Sensing of Environment 113(10), pp. 2152-2163. Nussberger, C., 2012. Using LiDAR intensity for surface characterisation in an alpine environment. Msc thesis, University of Zurich, Department of Geography, Remote Sensing Laboratories (RSL). Supervisor: Felix Morsdorf.

OPALS, 2016. Orientation and Processing of Airborne Laser Scanning data (product homepage). Department of Geodesy and Geoinformation - Research Groups Photogrammetry and Remote Sensing. http://geo.tuwien.ac.at/opals (16 Apr. 2016). Reusen, I., Kempeneers, P., Ceamanos, X., Bachmann, M., Kerr, G., de Miguel, E., Morsdorf, F., Kuekenbrink, D., Warren, M., Hanus, J., Carmon, N., Ben-Dor, E., Briese, C., Pfeifer, N. and Roncat, A., 2017. Airborne hyperspectral imagery and laser scanning data for improved processing and interpretation. EUFAR handbook. Supplement chapter published on-line. URL: tba.

Riegl LMS, 2016. Homepage of the company RIEGL Laser Measurement Systems GmbH. http://www.riegl.com. (16 Apr. 2016).

Roncat, A., 2014. Backscatter Signal Analysis of Small-Footprint Full-Waveform Lidar Data. PhD thesis. Supervisors: Norbert Pfeifer (TU Vienna), Uwe Stilla (TU Munich).

Roncat, A., Morsdorf, F., Briese, C., Wagner, W. and Pfeifer, N., 2014. Laser Pulse Interaction with Forest Canopy: Geometric and Radiometric Issues. Managing Forest Ecosystems, Vol. 27, Springer Netherlands, Dordrecht, The Netherlands, chapter 2, pp. 19-41.

Roncat, A., Pfeifer, N. and Briese, C., 2012. A linear approach for radiometric calibration of full-waveform Lidar data. In: Proc. SPIE 8537, Image and Signal Processing for Remote Sensing XVIII.

Schneider, F. D., Leiterer, R., Morsdorf, F., Gastellu-Etchegorry, J.-P., Lauret, N., Pfeifer, N. and Schaepman, M. E., 2014. Simulating imaging spectrometer data: 3D forest modeling based on LiDAR and in situ data. Remote Sensing of Environment 152, pp. 235-250.

Teledyne Optech Inc., 2017. Homepage of the company Teledyne Optech Inc. Last accessed: April 2017. 
Wagner, W., 2010. Radiometric calibration of small-footprint full-waveform airborne laser scanner measurements: Basic physical concepts. ISPRS Journal of Photogrammetry and Remote Sensing 65(6, ISPRS Centenary Celebration Issue), pp. 505-513.

Wagner, W., Ullrich, A., Ducic, V., Melzer, T. and Studnicka, N., 2006. Gaussian decomposition and calibration of a novel smallfootprint full-waveform digitising airborne laser scanner. ISPRS Journal of Photogrammetry and Remote Sensing 60(2), pp. 100 112 .

Wallace, A., McCarthy, A., Nichol, C., Ren, X., Morak, S., Martinez-Ramirez, D., Woodhouse, I. and Buller, G., 2014. Design and evaluation of multispectral LiDAR for the recovery of arboreal parameters. IEEE Transactions on Geoscience and Remote Sensing 52(8), pp. 4942-4954. 